\title{
Maytenus ovatus (schweinf.) An African Medicinal Plant Yielding Potential Anti-cancer Drugs
}

\author{
Vasanthakumar $\mathbf{K}^{1}$, Sumesh Kumar $\mathbf{S}^{* 2}$ and Tsegay Shimelis ${ }^{3}$ \\ ${ }^{1}$ Professor of the Horticulture Program, Haramaya University, Ethiopia \\ ${ }^{2}$ Asst Professor in Psychiatric Nursing, Haramaya University, Ethiopia \\ ${ }^{3}$ Graduate Assistant of the Horticulture Program, Haramaya University, Ethiopia
}

Received: December 01, 2017; Published: December 06, 2017

*Corresponding author: S Sumesh Kumar, Asst Professor in Psychiatric Nursing, School Of Nursing and Midwifery, Haramaya University, Ethiopia, Tel : 251937480242; Email: getsumesh2007@gmail.com

\section{Introduction}

Maytenus ovatus (Schweinf.) of the family Celastraceous is a shrub usually spiny with whitish flowers bearing reddish fruits and is widespread in the savannah regions of tropical Africa [1]. Mountains and sub-mountainous regions of African countries, viz., Ethiopia, Kenya, Tanzania, Uganda, Mozambique and others are wild habitats for the species, Maytenus ovatus, M. serratus, M. heterophylla and M. senegalensis [2]. Maytansine, a benzo-ansamacrolide (ansamycin antibiotic) is a highly potent microtubuletargeted compound that induces mitotic arrest and kills tumor cells at sub-nano-molar concentrations was originally isolated from the Ethiopian shrub, Maytenus ovatus. Maytansine binds to tubulin at the rhizoxin binding site. It inhibits microtubule assembly, induces microtubule disassembly, and disrupts mitosis. Maytansine exhibits cytotoxicity against many tumor cell lines and also inhibit tumor growth in vivo [3]. Since the discovery of Maytansine from Maytenus ovatus in 1972 as a potent cytotoxic agent, further 53 more maytansinoids have been identified from wild plants, microorganisms and mosses [4].

\section{Results and Discussion}

Maytansine, the highly cytotoxic natural product, could not succeed as an anticancer agent in earlier clinical trials conducted on humans because of systemic toxicity. The potent cell killing ability of maytansine was further tested in a targeted delivery approach for the selective destruction of cancer cells. A series of new maytansinoids, bearing a disulfide or thiol substituents were developed synthetically. Several of these maytansinoids were found to be even more potent in in-vivo experiments than maytansine. The targeted delivery of these maytansinoids, using monoclonal antibodies, resulted in high, specific killing of the targeted cancer cells in-vivo and remarkable antitumor activity in-vivo [5]. Some plants that indicate potential as an anticancer agent in laboratorybased in-vivo research including species of Maytenus are currently being studied extensively.
There can be many years between promising laboratory work and the availability of an effective anti-cancer drug. In the 1950's scientists began systematically examining natural organisms as a source of useful anti-cancer substances [6]. It has recently been argued that "the use of natural products has been the single most successful strategy in the discovery of novel anti-cancer medicines". These phyto-chemicals that is selectively more toxic to cancer cells than normal cells have been used in screening programs and are developed as potential chemotherapy drugs. Cancer is a malignant neoplastic disease characterized by uncontrolled growth of cells with the ability of the cells to migrate and spread to distant sites [7]. The most commonly occurring cancers are carcinomas while sarcomas, leukemias, lymphomas, melanomas and gliomas also pose big threat to human lives in the present day life all over the world.

Maytansinoids exhibit broad spectrum activity in ultra low concentrations (nanogram to microgram ranges). Early work on maytansine, the most widely studied of this series was hampered by exceptionally low yields $(0.2 \mathrm{mg} / \mathrm{kg}$ of plant part) of this compound from Maytenus species. Higher yields of maytansine $(12 \mathrm{mg} / \mathrm{kg}$ ) have been obtained from Putter1ickia verrucosa also of the family Ce1astraceae [8]. In a clinical trial, toxicity of maytansine was manifested by profound weakness; nausea and prolonged diarrhea to the extent that a few patients refused further treatment. But much more beneficial antitumor responses were observed by the administration of maytansine and its derivatives/ analogues and hence this group of compounds is undergoing extensive evaluation in current clinical oncology experiments.

\section{Background of the Invention}

United States Patent Number 3,896,111 of July 22, 1975, awarded to Kupchan [9], it was disclosed that certain African woods, in particular Maytenus ovatus and M. buchananii contain certain factors which demonstrated significant anti-leukemic activity 
in microgram/kilogram level. One of these factors, the chemical structure of which was disclosed in the patent was identified as "maytansine". The starting material for the development of maytansine based drugs by the procedures of the invention of Kupchan [9] is maytansine containing plant material, suitably woody portions of stem and bark. The preferred sources are wood from Maytenus ovatus, Maytenus buchananii and Putterlickia verrucosa. Wood of these plants is ground on a hammer mill to give slivers of a size of the order of $1 \mathrm{~cm} \times 1 \mathrm{~mm}$, but also includes larger slivers and dust particles.

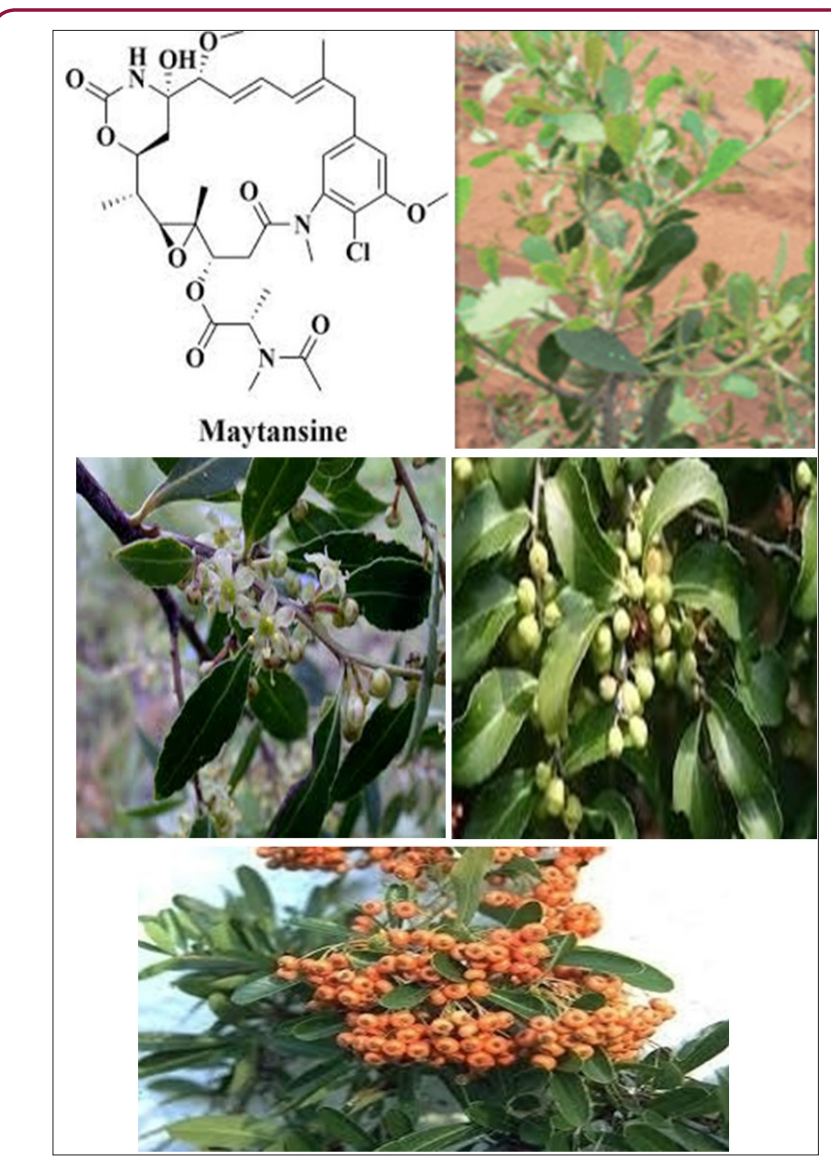

Figure 1:

The wood chips are processed in batches of approximately $1,400 \mathrm{~kg}$ of wood and are extracted with ethanol suitably containing up to about $5 \%$ by weight of moisture. The process also utilizes approximately 5,500 to 6,500 liters of extracting solvent per $1,400 \mathrm{~kg}$ batch of wood. Extraction is carried out in a recycling, large scale soxhlet type apparatus over a time of approximately 100 hours. The solvent is removed from the extracted mass to yield an initial crude isolate (corresponding to Kupchan fraction) of the order of 25 to 30 grams of extract per kilogram of charged wood and by further purification maytansine is isolated. Maytansine, a benzo-ansa-macrolide, first isolated from the bark of the Ethiopian shrub Maytenus ovatus is a vital cytotoxic agent and its derivatives bind to tubulin near the Vinca alkaloid binding site. Two maytansine derivatives, emtansine also referred to as DM 1 and ravtansine also referred to as DM 4 have been widely used in combination with reversible and irreversible linkers [10](Figure 1).
Trastuzumab emtansine (T-DM1; Roche in partnership with ImmunoGen) which received marketing patent in 2013 is a human epidermal growth factor receptor drug [11]. As shown in preclinical studies, the drug combines the distinct mechanisms of action of both DM1 and trastuzumab, and has antitumor activity in experimental human tumor models. T-DM1 has been approved as a secondline treatment for breast cancer patients that have previously failed to respond to therapy with trastuzumab chemotherapy. SAR3419 (Sanofi in collaboration with ImmunoGen) is another representative example of a maytansine-based ADC (Antibody Drug Conjugate) and this drug in clinical trials has demonstrated a response rate more than $70 \%$ in large B-cell lymphoma patients. Most of the African cultures have a verbal tradition and therefore, written information on cultural features in the past are not so readily available from Africa as from many other parts of the world.

The ethno-botanical information on the uses of these plants was sometimes documented on herbarium labels and, in this way, ethno-botanical information on a number of plants began to accumulate. Systematic accounts in written form dealing with medicinal plants in Africa are of a fairly recent date, while reports dealing with ethno-pharmacological aspects are more recent. A number of traditional national pharmacopeias have appeared, starting with the Madagascar Pharmacopeia in 1957 and research in the field of ethno-botany and ethno-pharmacology has developed rapidly in many African countries. The African Pharmacopoeia, covering traditional medicine of many African countries, has been published by the Scientific Technical Research Commission of the Organization of African Unity, starting with volume 1 in 1985.

Recently, the Association for African Medicinal Plants Standards, from Mauritius, started the publication of Monographs on medicinal plants which provide botanical, phyto-chemical, pharmacological and commercial information on the most important medicinal plants used in Africa. In Africa, the ethno-pharmacological and botanical knowledge on the uses of medicinal plants is often orally passed down from generation to generation. Although traditional medicine has been recognized as a part of primary health care programs in many African countries, there is a need to evaluate scientifically the crude extracts of plants for their medicinal and pharmaco-dynamic properties, clinical usefulness and toxicological potential.

\section{Mertansine, a semi-synthetic derivative of Maytansine}

Mertansine, also called DM1 (and in some of its forms emtansine), is a thiol-containing maytansinoid that for therapeutic purposes is attached to a monoclonal antibody through reaction of the thiol group with a linker structure to create an antibodydrug conjugate (ADC). ADCs with this design include trastuzumab emtansine, lorvotuzumab mertansine, and cantuzumab mertansine. Some of these compounds are still experimental; many others are in regular clinical use (Peter, 2013) [12].

\section{a. Mechanism of action of Mertansine}

Mertansine is a tubulin inhibitor, meaning that it inhibits the assembly of microtubules by binding to tubulin (at the rhizoxin 
binding site). The monoclonal antibody binds specifically to a structure (usually a protein) occurring in a tumour, thus directing mertansine into the tumour cells. This concept is called targeted cancer chemo-therapy.

\section{Conclusion}

Ethiopian forests and wild habitats are potential sources of rich bio-diversity which include highly potential medicinal plants that can be utilized in the traditional practices of Ethiopia and at the same time can be exploited in the modern systems of medicine. Killer ailments like, cardio-vascular diseases, cancer, HIV, diabetes is posing big threat to human lives not only in Africa but all throughout the world. In this context, more and more medicinal plants need to be explored for their cultivation and utilization in human health care. The scientific community involved in the discovery and isolation of Maytansine from Maytenus ovatus for the treatment of leukemia; breast and lung cancers deserve high admiration. The search for more medicinal plants needs to be undertaken in Ethiopia for utilization in different aspects of human healthcare.

\section{References}

1. Bekele E (2007) Study on Actual Situation of Medicinal Plants in Ethiopia. Japan Association of International Collaboration of Agriculture and Forestry.

2. Silva GD, Serrano R, Silva O (2011) Maytenus heterophylla and Maytenus senegalensis, two traditional herbal medicines. J Nat Sci Biol Med 2(10): $59-65$.
3. Kupchan SM, Komoda Y, Court WA, Thomas GJ, Bryan RF (1972) Tumor Inhibitors, Maytansine, a novel antileukemic ansa macrolide from Maytenus ovatus. J Amer Chem Soc 94(4): 1354-1356.

4. Kupchan SM (1975) Advances in the chemistry of tumor inhibitory natural products. Rec Adv Phytochem 9: 167-188.

5. Wayne CW, Sharon DW, Emily EC, Ravi VJ, Leece BA, et al. (2006) Semisynthetic Maytansine Analogues for the Targeted Treatment of Cancer. J Med Chem 49(4): 4392-4408.

6. Crag GM, Newman DJ (2005) Plants as source of anti-cancer agents. Journal of Ethno pharmacology 100(1-2): 72-79.

7. Modhumita G, Manisha T, Krish M (2009) Novel Therapeutic Agents from Plants. Taylor and Francis LLC.

8. Richard GP, Cecil RS (2010) Anti-tumor Agents from Higher Plants, US Department of Agriculture, Illinois, USA.

9. Kupchan SM, Sneden AT, Branfman GA, Hourie LI, Schnaitman TC, et al. (1978) Structural requirements for anti-leukemic activity among the naturally occurring and semi-synthetic maytansinoids. J Med Chem 21(1): 31- 37.

10. Manu L, Emin O, Leslie W, Mary AJ, Wilhelm S, et al. (2010) Maytansine and Cellular Metabolites Strongly Supress Microtuble Dynamics by Binding Microtubles. Mol Cancer Ther 9(10): 2689 -2698.

11. Mario W, Girish S, Wang B, Lu D, Krop IE, et al. (2012) Clinical pharmacology of trastuzumab emtansine, an antibody drug conjugate for treatment of HER2- positive cancer. Cancer Chemother Pharmacol 69(5): 1229-1240.

12. Peter CH (2013) Mertansine, National Cancer Institute Bulletin, USA.

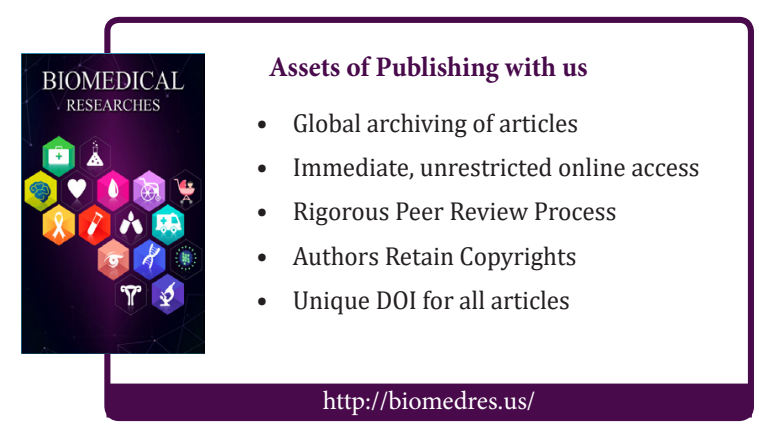

